\title{
Increasing The Efficiency of The Cub Engine Assembly Lines In The Automotive Industry Using Ranked Positional Weight
}

\author{
Inaki Maulida Hakim ${ }^{1, a}$, Syarafi Auzan Mu'min², and Rolina Oktapiani Zaqiah ${ }^{3}$ \\ ${ }^{1 a, 2,3}$ Department of Industrial Engineering,Faculty of Engineering, Universitas Indonesia, Depok, \\ Indonesia
}

\begin{abstract}
In this modern era, the competition among the manufacturing industry, especially in the automotive sector will become increasingly tight which causes companies need to innovate so that satisfaction of the consumer can be maintained. The production process will be an important aspect in the automotive industry to maintain the quality of products and ensure consumer demand can be fulfilled. The problems that often occur in the production process is in the form of production flow constraints caused by workload unbalanced in the assembly lines. The imbalance causes the assembly lines do not run in a cycle time that is determined, so that consumer demand can not be meet in the right amount and companies need to spend more to mitigate them. Therefore, this study was conducted to balance workload on the assembly line by using line balancing form Ranked Positional Weight (RPW) with a subsequent increase in the efficiency and productivity of assembly line that affect production process runs without any contraints.
\end{abstract}

\section{Introduction}

Nowadays, people tend to use their own vehicles such car and motorcycle instead of public transportation. For improvement in automotive industry, must be have strategy each company to prepare Industry 4.0. Currently in Indonesia, the type of motorcycle vehicle is the transportation that is most widely used by community due to ease of use and the most important is cost and time friendly. Motorcycle become relatively important of transportation for Indonesian society and resulting in an increase number of demand for motorcycle each year. The trend of an increasing number of motor vehicles in Indonesia every year, this has resulted in automotive companies, especially in the manufacturing of the motor so it needs to be improvement impacting the company to meet the market demand continues to increase. Optimal use of available resources and also improving the quality of the product will provide cost reduction and increase the level of customer satisfaction so that the profit for the company can continue to increase. The balance of production line starts from mass production, where production process must have a balance of time between each work station. Line balancing learn how balancing in assembly lines

\footnotetext{
${ }^{a}$ Corresponding author : inakimhakim@eng.ui.ac.id
} 
can occur with leveler existing workload for each operator. The term line balancing is a method to assign jobs to workstations interrelated in a single production line so that each station has a time not exceeding the cycle time of work stations. Linkage number of jobs in an assembly lines need to be considered in determining the division of jobs into each work station. Relationships or interconnections between work and other work is described in a preliminary precedence diagram or chart, while it is called precedence relations job or precedence network (Bedworth, 1982).

The main problems that often occurs in assembly lines such as the occurrence of constraints in the system that is closely related to maintenance. Balancing workload on multiple workstations with the aim of achieving high efficiency and meet production planning that has been made. There are some symptoms of imbalance production line that includes differences in the performance of a work station with high levels of idle time and a work in process at several work station.To improve efficiency and productivity, can be achieved by reducing the manufacturing time required to produce the final product by reducing the number of workstations or both (Hamza, 2013). Therefore, the aims of this study is to increase the productivity and efficiency of the assembly line using line balancing method which focused on the cub engine line and used some parameters such as line efficiency, idle time, and smoothness index.

\section{Methodology}

Line balancing is usually performed to minimize the imbalance between machines or personnel in order to meet the desired output of the assembly line. Finish line balancing problem, industry management should be able to know about the working methods, equipment, machinery, and personnel used in the work process. In addition, information about the time required for each assembly line and precedence relationship between activities is the arrangement and sequence of the various tasks that need to be done. There are some terms that are commonly used in the line balancing. Here are the terms in question

\subsection{Precedence diagram}

Precedence diagram used before stepping on the completion method of line balancing. Precedence diagram is actually a graphic picture of the sequence of work operations, as well as dependence on other working operation whose purpose was to facilitate the control and planning of activities associated therewith, while the mark is used in precedence diagram is as follows:

a. The circle symbol with the letter or number on it to facilitaties identification on a process operation.

b. The arrow shows the dependence and sequence of process operations. This operation is in the base of the arrow means working operations precedence that of the arrowhead.

c. The figure above the circle symbol is the standard time it takes to complete each operation process.

\subsection{Assemble Product}

Assemble Product is a product that passes order in which workstation, each workstation provides a specific process to complete final product at the final assembly. 


\subsection{Idle Time}

Where operator or worker waiting to perform work processes or operations that will be done next. The difference or distinction between Cycle time (CT) and Station Time (ST), or CT reduced Station Time (ST).

$$
\text { Idle Time }=n . W s-\sum_{\mathrm{i}=1}^{\mathrm{n}} W_{\mathrm{i}}
$$

$\mathrm{N} \quad=$ Number of workstation.

Ws = Highest workstation time

$\mathrm{Wi}=$ Time on workstation

$\mathrm{I} \quad=1,2,3, \ldots \mathrm{n}$

\subsection{Balance delay}

Balance delay is measure of inefficiency resulting trajectory of the time unemployed actually caused the allocation is less than perfect work stations. Balance delay can be formulated as follows:

$$
D=\frac{n \cdot C-\sum t_{\mathrm{i}}}{\left(n . t_{\mathrm{i}}\right)} \times 100 \%
$$

$\mathrm{D} \quad=$ Balance delay $(\%)$

$\mathrm{N} \quad$ Number of workstation

$\sum \mathrm{t}_{\mathrm{i}}=$ Sum of all operation time

$\mathrm{t}_{\mathrm{i}} \quad=$ Operation time

$\mathrm{C} \quad$ Cycle time

\subsection{Workstation Efficiency}

Workstation efficiency is ratio between operating time per work station (Wi) and the largest work station operating time (Ws). The efficiency of the work station can be formulated as follows:

$$
\text { Workstation Efficiency }=\frac{W_{\mathrm{i}}}{W_{\mathrm{s}}} \times 100 \%
$$

\subsection{Line Efficiency}

Line efficiency is ratio of total time divided by the work station cycle multiplied on the number of workstations or the number of workstations efficiency divided by the number of workstations. Line efficiency can be formulated as follows:

$$
\text { Line Efficiency }=\frac{\sum_{\mathrm{i}=1}^{\mathrm{k}} S T_{\mathrm{i}}}{\mathrm{k} \cdot \mathrm{CT}} \times 100 \%
$$

$\mathrm{ST}_{\mathrm{i}}=$ Time of workstation $\mathrm{i}$

$\mathrm{k} \quad=$ Number of workstation

$\mathrm{CT}=$ Cycle time

\subsection{Minimum Work Station Required}

Workstation is a place on the assembly line where the assembly process is done. After determining the cycle time interval, the number of work stations that can efficiently determined by the formula: 


$$
\operatorname{kmin}=\frac{\sum_{\mathrm{i}=1}^{\mathrm{k}} t_{\mathrm{i}}}{\mathrm{CT}}
$$

\subsection{Smoothness Index}

Smoothness index (SI) is an index that indicates the relative smoothness of a specific assembly line balancing.

$$
S I=\sqrt{\sum_{\mathrm{i}=1}^{\mathrm{k}}\left(S T_{\max }-S T_{\mathrm{i}}\right)^{2}}
$$

$\mathrm{ST}_{\max } \quad=$ Maximum workstation time

$\mathrm{ST}_{\mathrm{i}} \quad=$ Time of workstation $\mathrm{i}$

Steps in this method used Ranked Positional Weight Method is as follows (5) :

1. Make a precedence diagram.

2. Determine ranking position (positional weight) for each element of the work (a ranking position of a touch operation on the longest flow time of start of operation until the end of network).

3. Sort elements of work based on ranking position in step number 2. Elements of work with the highest ranking position most sorted first.

4. The process of placement of elements of work at workstation, where elements of work with the rank and position of the highest order who placed first.

5. If the workstations are the remaining time after the placing of an operation, place the next sequence operation at workstation during the operation do not violate in precedence relationships, time do not exceed on workstation cycle time.

6. Repeat the steps 4 and 5 until all elements of the work has been already placed at workstation.

\section{Case Study of Automotive Industry}

This case study is based upon a real problem from the automotive industry which is one of the largest motorcycle manufacturers. The manufacture has a problem in their production line which impact on the company's looses by not able to fulfill customer orders also increased overtime.

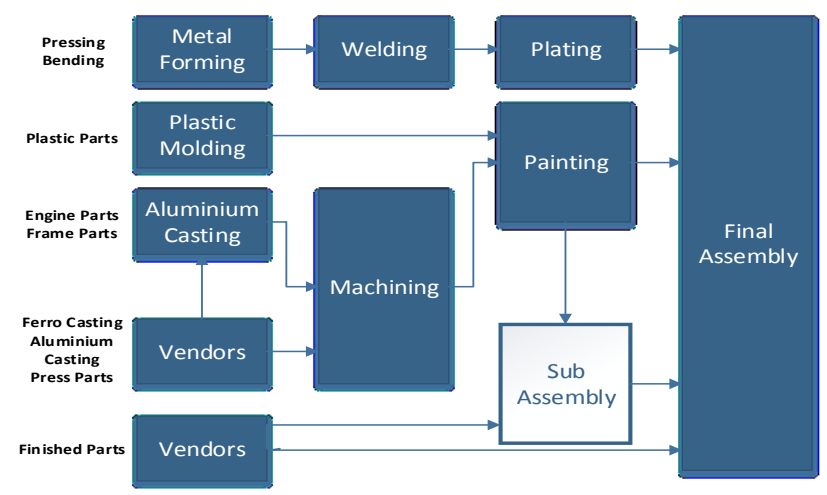

Fig. 1. Production flow of the manufacture

Although the entire section that is in production systems is an important factor for the sustainability of production lines, there are two sections is a major factor that is sub 
assembly and final assembly. Sub assembly is responsible for generating products such as engine and tire while the final assembly section was responsible for assembling all products from previous section into final product that is motorcycle. Both sections which can be considered important due to the high levels of liability and usability compared to other sections as a result if there is a delay in the sub assembly or final assembly, then the entire production system will also experience delays due to the minimum time available for both sections to be able to repair and fulfill desired order. Particularly in sub assembly section, delay often caused by imbalance production assembly lines that can be seen from the unemployed workers in several work stations, while some other work stations are work optimally. This resulted in the production system is running not efficiently and effectively

\subsection{Results}

Table 1 shows a comparison of the level of performance of the assembly line with the actual conditions of assembly lines that have been carried out line balancing using parameters that are in line balancing.

Table 2. Comparison of performance levels actual condition with assembly line balancing line results

\begin{tabular}{|c|c|c|}
\hline $\begin{array}{c}\text { Parameter Line } \\
\text { Balancing }\end{array}$ & Before Improvement & After Improvement \\
\hline Line Efficiency & $83,12 \%$ & $91,43 \%$ \\
\hline Number of Work Station & 22 & 20 \\
\hline Smoothness Index & 41,59 & 14,99 \\
\hline WS Efficiency & $76,52 \%$ & $91,71 \%$ \\
\hline Idle Time & 168,29 & 49,58 \\
\hline Balance Delay & $16,88 \%$ & $8,57 \%$ \\
\hline
\end{tabular}

Based on comparison of the level of performance of Table 1 shows that the balance of the assembly lines by using line balancing is generally better than the current condition of the assembly line. Every parameter of line balancing will be further analyzed as follows:

1. Line Efficiency

Line Efficiency is the level of efficiency of the assembly line, expressed as the ratio between the time spent by the assembly line to the available working time is the cycle time. By having a high level of efficiency, it can be said that each station has a working time approached predetermined cycle time so that the higher level of efficiency of assembly line, performance of assembly lines will be more optimal. Based on the calculations, efficiency improvement trajectory of the actual condition from $83.12 \%$ increased until $91.43 \%$ using the method of line balancing.

2. The number of workstation

The number of workstations used will affect the planning of expenditures made by the company so as to more reduction in the required workstations will have an impact on cost reduction for companies and profitable for them financially. After the line balancing on assembly line, there is a reduction in number of workstations needed from 22 to 20 workstations resulting cost reduction for the company.

3. Smoothness Index

Smoothness Index is an index that has a relatively smooth running of the assembly lines of certain balance or equilibrium level of fluency of assembly line has been established. Value smoothness index increasingly close to zero suggest that the level smoothness of assembly line will get better and this contributes to index of delay on production process. The value of the smoothness index decreased assembly line where value on current conditions that amounted to 41.59 to 14.99 so that it can be concluded that the smooth running of assembly lines is increasing and prevent the occurrence of delay production. 
4. Workstation Efficiency

Workstation efficiency is a high level of efficiency is expressed by the ratio of a workstation with the greatest time working station for the entire workstation. Workstations can describe balancing efficiency of allocation of workload that is by increasing the value of the workstation efficiency, the labor time required for each workstation will be close to the largest working time from one workstation so that the workload of each work station can be said to be more balanced. Condition of assembly lines currently have a workstation efficiency value of $76.52 \%$ to $92.71 \%$ after the line balancing that with increase in this parameter states that the allocation of existing workload on assembly line machines cub become more balanced.

5. Idle Time

Idle Time is total waiting time required by work stations to carry out specified work operation. By decreasing value of idle time, waiting time required by the operator will also be getting a little bit so working process can be run faster and increase productivity on workstation. Based on the calculation result, adecline in the value of idle time on assembly lines of 168.29 seconds became 49.58 seconds.

6. Balance Delay

Balance delay is ratio between idle time on assembly line with time available. The value of balance delay starting from percentage of idle time owned production process since the time of components entering the first workstation to workstation last. If value of balance delay to zero then the level of performance of assembly line can be expressed better as time delay on all wor stations will be smaller than time available. The value of balance delay obtained from the calculation amounted to $8.57 \%$ where value is decreased from value balance delay in actual conditions which amounted to $16.88 \%$.

\section{Summary and Conclusion}

By performing line balancing methods using Ranked Positional Weight on the assembly line, there was an increase in the level of performance of assembly lines with an efficiency of $91.43 \%$, number of workstations required as many as 20 , the index of smoothness index of 14.99 , the level of efficiency workstation at $91.71 \%$, the value of idle time of 49.58 seconds, and the value of balance delay amounted to $8.57 \%$. The increase in line balancing parameter indicates that assembly line will run better than current assembly lines where the level of efficiency has a value of $83.12 \%$. Number of workstation required as many as 22 and index of smoothness index of 41.59 , the level of efficiency of workstations amounting to $76.52 \%$, the value of the idle time of 168.29 seconds, and balance delay value amounted to $8.57 \%$. With the increased performance of assembly line so can make increase of $t$ efficiency and productivity which will surely impact production system as a whole so that the company can meet demand of consumers constantly as well as reduce cost. Investigate further associated with other aspects such as layout of production process, maintenance of machinery and equipment also psychologically assessment for employees.

\section{Acknowledgements}

This work is supported by Hibah PITTA 2018 funded by DRPM Universitas Indonesia, No. 2453/UN2.R3.1/HKP.05.00/2018. 


\section{References}

1. Barnes.Ralph.M, Motion and Time Study: Design and Measurement of Work, (John Wiley and Sons, 1980)

2. D. Bedworth, Integrated Production and Planning Control (John Wiley and Sons, 1982)

3. Hong-Jinh Cang,Tung-Meng Chang. (Tamkang Journal of Science and Engineering,2010)

4. R. Hamza, A. Jassim, G. Per. Eng. Mng. E 2, 70 (2013)

5. S. N. Chapman, The Fundamentals of Production Planning and Control (Pearson, London, 2005)

6. S. Ghutukade, S. Sawant, I. J. Ad. Eng. Res. E 5, 1 (2013)

7. A. Elsayed, Analysis and Control of Production System (Prentice Hall, New Jersey, 1994) 